LUCAS MORELLI

\title{
RELAÇÃO DE CONSUMO \\ E O CONTRATO DE CLOUD COMPUTING
}

DISSERTAÇÃO (MESTRADO)

ORIENTADOR: FERNANDO CAMPOS SCAFF

UNIVERSIDADE DE SÃO PAULO

FACULDADE DE DIREITO

SÃO PAULO - SP

2018 

UNIVERSIDADE DE SÃO PAULO

FACULDADE DE DIREITO

\section{RELAÇÃO DE CONSUMO E O CONTRATO DE CLOUD COMPUTING}

Lucas Morelli

Dissertação apresentada à Banca Examinadora do Programa de Pós-Graduação em Direito, da Faculdade de Direito da Universidade de São Paulo, como exigência parcial para a obtenção do título de Mestre em Direito, na área de concentração em Direito Civil.

Orientador: Professor Titular dr. Fernando Campos Scaff.

(VERSÃO ORIGINAL)

V.1

São Paulo

2018 

Nome: MORELLI, Lucas

Título: Relação de Consumo e o Contrato de Cloud Computing

Dissertação de Mestrado apresentada à Banca Examinadora da Faculdade de Direito da Universidade de São Paulo, como exigência parcial para a obtenção do título de Mestre em Direito, na área de concentração de Direito Civil, sob a orientação do Professor tituar Fernando Campos Scaff.

Aprovado em:

Banca Examinadora:

Prof. Dr. Instituição:

Julgamento: Assinatura:

Prof. Dr. Instituição:

Julgamento: Assinatura:

Prof. Dr. Instituição:

Julgamento: Assinatura:

Prof. Dr. Instituição: Julgamento: Assinatura: 



\section{AGRADECIMENTOS}

Desde o início de minha graduação em 2009, foram muitas as pessoas que contribuíram para a minha formação, seja como profissional, seja como pessoa. As primeiras são meus queridos pais José Antônio Morelli e Miriam Varanda Morelli e meu querido irmão Samuel Morelli, que sempre me apoiaram e, sem eles, jamais conseguiria ter alcançado esse objetivo.

No âmbito acadêmico, muitos professores me inspiraram e hoje, certamente, são meus queridos exemplos, sendo eles, primeiramente meu querido orientador professor Fernando Campos Scaff, que confiou na minha capacidade de pesquisa e profissional, o querido professor Bernardo Bissoto Queiroz de Moraes, que acompanhou minha trajetória acadêmica desde o primeiro ano da graduação até o presente e o professor André Rodrigues Corrêa, com o qual tive a imensa honra de trabalhar como monitor, mais que um chefe, tornou-se um querido amigo.

Ao estimado dr. Guilherme Ferreira da Cruz, exemplo excepcional que me inspirou nos caminhos da pesquisa do direito do consumidor e moldou o profissional que sou hoje.

Agradeço aos amigos, irmãos de pesquisa, Gabriela Paredes Arcentales, Barbara Gomes Navas, Nina Chaim Meloni e Flávio Santos de Melo Oliveira, pelo companheirismo e incentivo que fizeram toda a diferença para o andamento e conclusão dessa dissertação, bem como aos queridos Tiago Antônio Baldasso, Solimar Cardoso, Mariane Baldrighi, João Henrique Conte Ramalho, Brenda de Souza Pedroso Machado e Suely Yoshimi Etagaki pelos inigualáveis conselhos.

De especial importância para um pesquisador advogado é o grande apoio dos escritórios em aceitar os turnos duplos e até triplos, meu especial agradecimento aos queridos profissionais Carlos Augusto Tortoro Júnior e Caio Medici Madureira.

Agradeço, por fim, a todos os amigos feitos na convivência proporcionada pela Faculdade de Direito do Largo de São Francisco e pela Fundação Getúlio Vargas, cujas contribuições para essa pesquisa foram incalculáveis, especialmente à corretora Ivania Valin pelo empenho na correção da presente dissertação. 



\section{RESUMO}

Morelli, L. Relação de Consumo e o Contrato de Cloud Computing. 2018. mestrado, Faculdade de direito, Universidade de São Paulo, São Paulo.

O presente trabalho analisa a relação contratual estabelecida nos contratos de Cloud computing, especificamente sob o suporte fático das relações de consumo. Para tanto, serão analisados os conceitos de contratos de bens informáticos, distinguindo-os do gênero dos contratos eletrônicos, bem como os novos mecanismos contratuais comandados por inteligência artificial que se utilizam da computação de nuvem para a automatização da tomada de faculdades contratuais, tratando-se dos chamados smart contracts e dos algoritmos contratuais. Após, se adentra na estruturação do negócio jurídico da computação de nuvem, sua natureza complexa de prestação de serviços e elemento disruptivo dos principais avanços tecnológicos na área tecnológica, os sujeitos da relação e da cadeia de fornecimento e as responsabilidades contratuais, esmiuçando referido contrato na hipótese das peculiaridades das relações de consumo e a vulnerabilidade tecnológica aplicada para consumidores/usuários pessoas físicas e jurídicas, empreendendo uma análise comparada da relação de consumo no Brasil, Europa e no sistema da Common Law.

Palavras-chave: Contratos - Novos Princípios Contratuais - Contrato Eletrônico Armazenamento de dados - Cloud computing - Direito do Consumidor - vulnerabilidade tecnológica - Empresa consumidora 



\begin{abstract}
This dissertation analyzes the contractual bound established in Cloud computing contracts, specifically under the consumer law. Therefore, will analyze the newest concepts of computer contracts, distinguishing them from the electronic contracts, as well as the new contractual mechanisms commanded by artificial intelligence that use information stored in Cloud computing to take contractual decisions, the so-called smart contracts and contractual algorithms. After, the structure of the legal business of Cloud computing will be analyze, taking into account its complex nature of service provider and the disruptive element as main technological advances, and the agents of the economic operation, supply chain and the contractual responsibilities under consumer law relations and the technological vulnerability applied to agents/users, doing a comparative analysis of the consumer law bound in Brazil, Europe and the Common Law system.
\end{abstract}

Keywords: Contracts - Contracts - New contractual principles - Electronic Contract - Data storage - Cloud computing - Consumer law - technological vulnerability 



\section{SUMÁRIO}

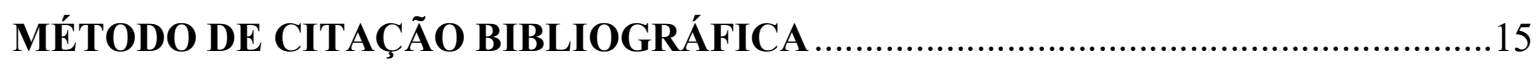

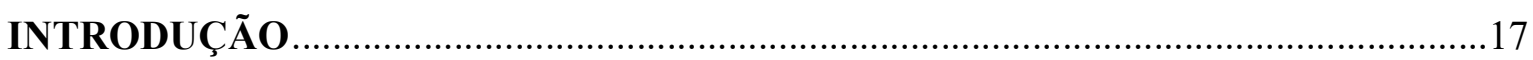

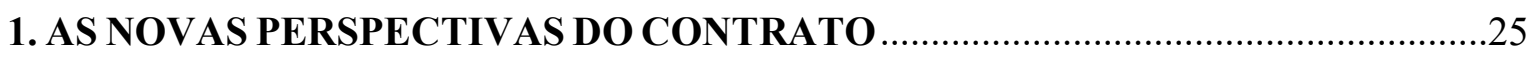

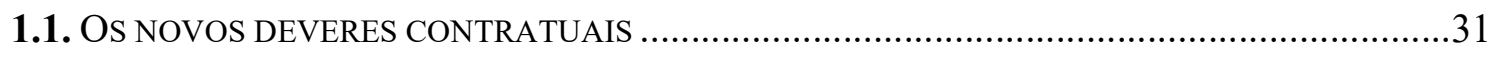

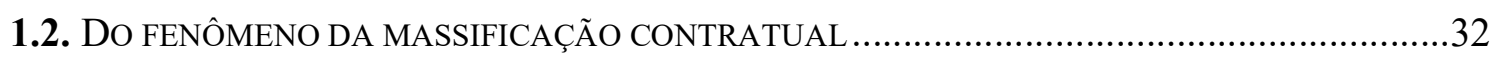

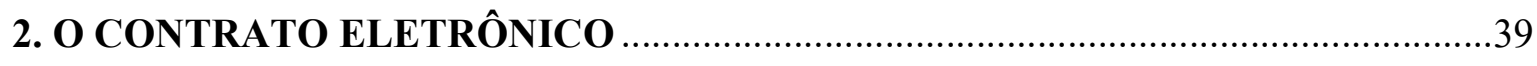

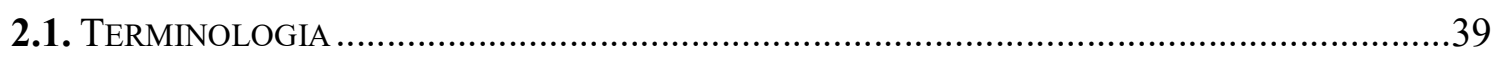

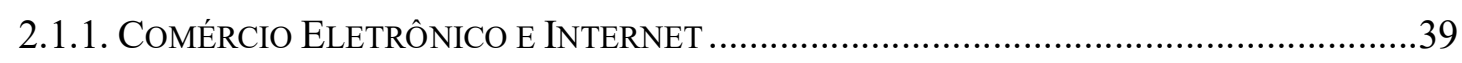

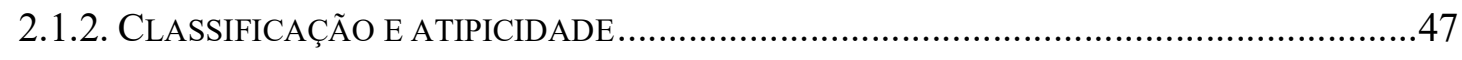

2.1.3. CONCEITOS CONTRATUAIS NO SISTEMA DA COMPUTAÇÃO .....................................54

2.1.3.1. OS BENS INFORMÁTICOS E A RELAÇÃO COM O NOVO MERCADO .............................54

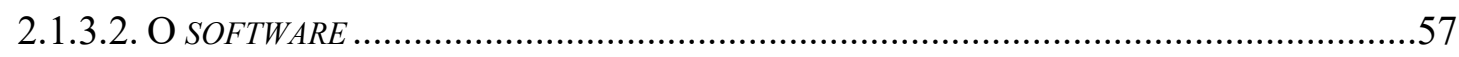

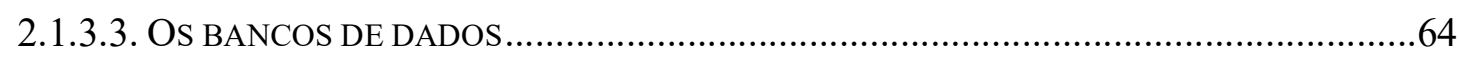

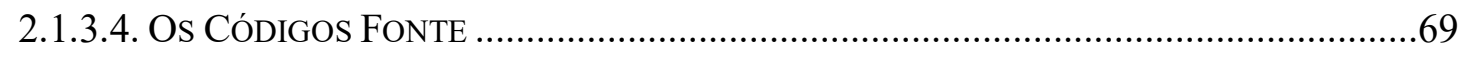

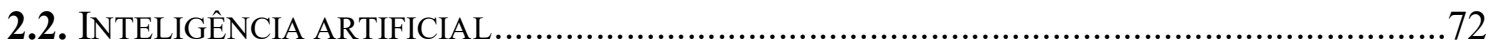

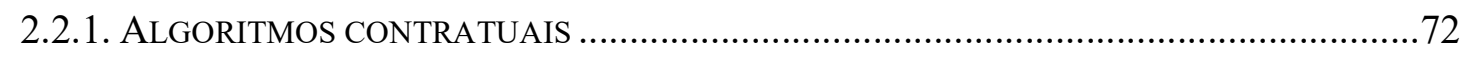

2.2.2. CONTRATOS INTELIGENTES: BLOCKCHAIN E O BITCOIN ….....................................8

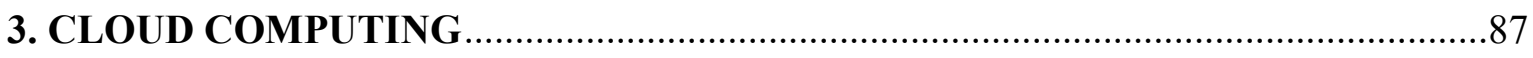

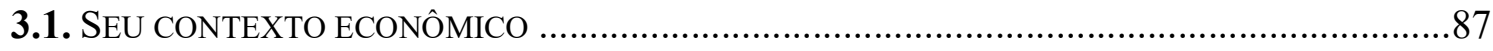

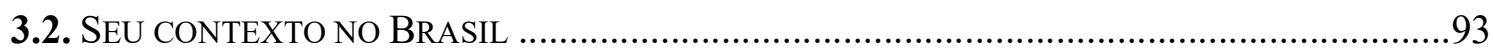

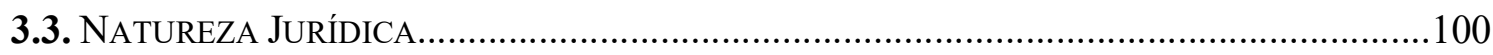

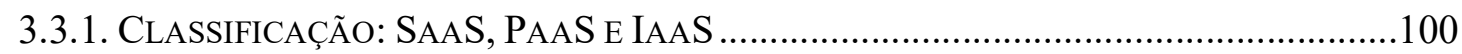

3.3.1.1. VIRTUALIZAÇÃO DE DADOS E PROCESSAMENTO ON DEMAND ...............................106

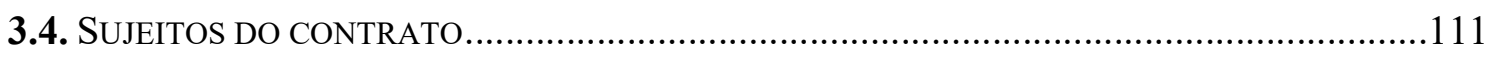

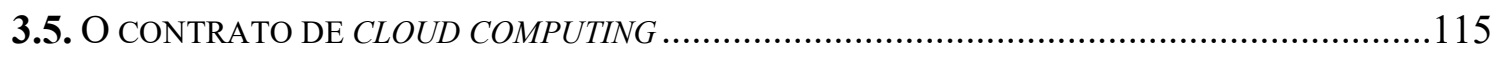


3.5.1 OS CONTRATOS DE OUTSOURCING E O CLOUD COMPUTING .118

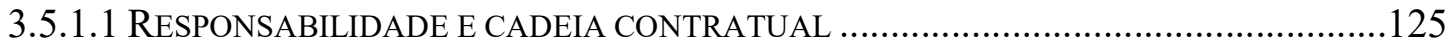

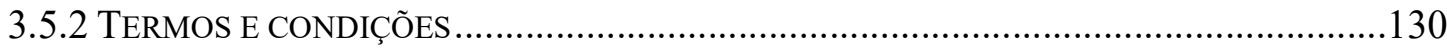

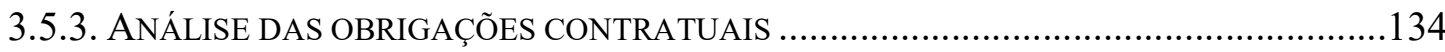

3.5.3.1. O ARMAZENAMENTO E O TRATAMENTO DE DADOS.............................................134

3.5.4 RISCO E RESPONSABILIDADE CONTRATUAL: “A CLICK TO TRAP”.............................141

3.5.5. A COMPUTAÇÃO DE NUVEM NO ÂMBITO PÚBLICO ...................................................145

4. RELAÇÃO DE CONSUMO NOS CONTRATOS DE CLOUD COMPUTING ..........148

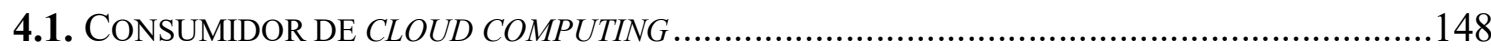

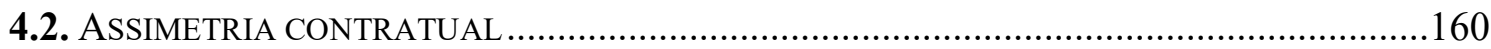

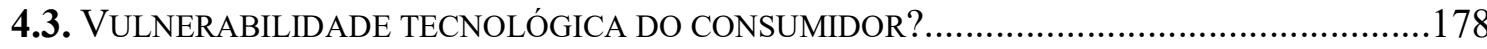

4.3.1 Os CONTRATOS B2B E B2C NO ÂMBITO DO DIREITO BRASILEIRO E ESTRANGEIRO 184

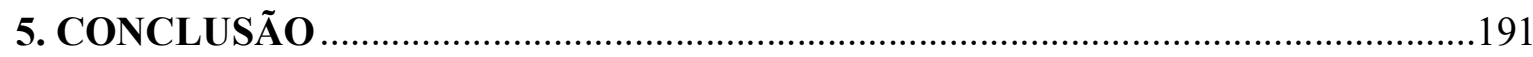

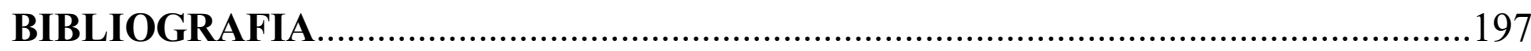




\section{MÉTODO DE CITAÇÃO BIBLIOGRÁFICA}

Os autores são citados pelo sobrenome, grafado em letras maiúsculas, seguido do prenome, abreviado. Depois, vêm as referências da Obra. O título está sempre grafado em itálico. Seguem o volume, a edição, o local da publicação, a editora, a data e, quando pertinente, a página, todos separados por vírgulas.

Os artigos insertos em revistas foram citados em itálico, seguidos pela indicação do periódico, do número de circulação, do ano e das páginas. Contudo, muitos desses trabalhos foram consultados pelo autor em banco de dados eletrônico disponibilizado pela editora Revista dos Tribunais, o qual permite o acesso a esses artigos em versão eletrônica que não possui paginação.

Também foram consultados muitas fontes eletrônicas e banco de dados Hein online e SSRN, cujas citações combinaram dois padrões de citação: APA (American Psychological Association) e MLA (Modern Language Association), primeiramente, grafando-se o nome do autor, seguido do título da obra em itálico, local de publicação, ano ou data de publicação, “disponível em” e indicando o lugar de armazenamento do documento ou mecanismo de identificação e endereçamento (URL - Uniform Resourse Locator) e a data do acesso ou consulta do documento.

Nas obras escritas em conjunto por dois autores, foram citados ambos. Nos trabalhos coletivos, citou-se o capítulo escrito pelo autor e, em seguida, o nome do coordenador, a obra e as respectivas páginas.

As teses e dissertações foram especificamente designadas como tal, seguidas pela instituição de ensino e departamento na qual foram defendidas e pela data.

As referências bibliográficas, quando já citadas no trabalho, serão grafadas de forma reduzida com a menção ao título da obra, seguido da expressão “op. cit.”, a nota correspondente em que a obra foi primeiramente citada e a paginação. 



\section{INTRODUÇÃO}

O objeto da presente dissertação se propõe a analisar um tipo contratual específico, o chamado contrato de Cloud Computing.

De fato, não basta à presente dissertação simplesmente adentrar-se de forma premeditada ao tema sem primeiramente ser entendido o contexto do referido trabalho, inserindo-o no campo de estudo do chamado direito digital ou cyberlaw para o direito americano.

Nesse ponto, quando dos inícios dos estudos no campo do direito digital, um fato interessante ocorreu nos Estados Unidos no simpósio "Law of Cyberspace", organizado na Universidade de Chicago, onde um dos palestrantes convidados, o juiz FranK H. EASTERBROOK, que deveria tratar do tema " Property in Cyberspace", proferiu na ocasião uma palestra originando o texto: "Cyberspace and the Law of the Horse", no qual condenou a especialização exagerada da ciência jurídica, equiparando o conceito de Cyberlaw com o conceito chamado por ele de "Law of the Horse", dissertando que, em corridas de cavalos, os danos causados estariam todos abrangidos pelas regras de indenização da Responsabilidade Civil (law of torts), não se criando pelo estudo do direito um campo exclusivo chamado "direito dos cavalos" ou "responsabilidade civil pelo dano ocasionado por cavalos", por exemplo. ${ }^{1}$

FRANK H. EASTERBROOK, por analogia, aplica sua linha de pensamento à propriedade intelectual na rede de computadores:

This leads directly to my principal conclusion: Develop a sound law of intellectual property, then apply it to computer networks. Problem: we do not know whether many features of existing law are optimal. Why seventeen years for patents, a lifetime plus some for copyrights, and forever for trademarks? Should these rights be strengthened or weakened? Why does copyright have the particular form it does? What sense can one make of the fuzzball factors for fair use? How can one make these rights more precise, and therefore facilitate Coasean bargains? Until we have answers to these questions, we cannot issue prescriptions for applications to computer networks. ${ }^{2}$

\footnotetext{
${ }^{1}$ Cyberspace And The Law of The Horse, University of Chicago Legal Forum no 207, 1996, pp.207-209.

${ }^{2}$ Cyberspace And The Law of The Horse, op. cit. (nota 1), pp. 208.
} 
O autor não defende a criação de Leis específicas sobre a propriedade intelectual no direito digital, entretanto, sugere que as Leis de propriedade intelectual sejam melhor trabalhadas, bem como, que sejam incluídos no rol dos direitos de propriedade os domínios de internet. Conclui o autor:

Property rights need to be better specified than that. Appropriation of names and trademarks would not be tolerated in the rest of the commercial or political world; why so for Internet addresses? (...) hat means three things: make rules clear; create property rights where now there are none; and facilitate the formation of bargaining institutions. Then let the world of cyberspace evolve as it will, and enjoy the benefits. $^{3}$

O autor simplifica bastante a questão da propriedade no direito digital, chegando inclusive a afirmar que haveriam questões legais mais controvertidas no âmbito da propriedade intelectual do que aquelas da propriedade intelectual na rede de computadores.

Indo além, o autor afirma que o contrato eletrônico, igualmente, em nada se diferenciaria de um contrato convencional, simplificando a discussão ao afirmar que a forma de adesão da contratação em nada pode afastar a justa expectativa do consumidor com relação às características efetivas dos produtos, ainda que as características expressas nos termos sejam outras. $^{4}$

Curioso que a opinião de FrANK H. EASTERBROOK foi objeto de um artigo resposta feito por LAWRENCE LESSIG por volta de três anos depois, no qual o mesmo rebate veementemente o primeiro autor: "I agree that our aim should be courses that "illuminate the entire law," but unlike Easterbrook, I believe that there is an important general point that comes from thinking in particular about how law and cyberspace connect" ${ }^{\text {. }}$

Para esse autor, o importante é a eficácia da Lei, de forma que algumas áreas do direito não prescindem de regulamentação específica, mas outras a exigem para uma maior eficácia, sendo esse o caso do direito digital. LAWRENCE LESSIG exemplifica citando a proibição do acesso à pornografia por menores de idade e afirma que, no mundo físico, é razoavelmente possível identificar menores de idade, ainda que eles busquem disfarçar-se, de forma que a

\footnotetext{
${ }^{3}$ Cyberspace And The Law of The Horse, op. cit. (nota 1), pp. 212.

${ }^{4}$ Cyberspace And The Law of The Horse, op. cit. (nota 1), pp. 214-216.

${ }^{5}$ Commentaries, The Law of The Horse: What Cyberlaw Might Teach, in Harvard Law Review, v. 113, p. 502.
} 
venda ou exibição de material proibido pode ser facilmente obstada. Entretanto, no universo digital, a identificação dos usuários não ocorre na forma "self-authenticating", assim, a legislação eficaz no mundo real, torna-se ineficaz no mundo digital, visto que o controle de idade mostra-se impossível no mundo digital, uma vez que os acessos de usuários a determinado site ocorre de forma igual para todos, utilizando-se dos mesmos protocolos. ${ }^{6}$

Outro exemplo do autor versa sobre privacidade: quando o consumidor entra em uma loja no mundo físico, o segurança desse estabelecimento pode lhe perguntar o nome, um funcionário pode lhe questionar qual a identidade do cliente, uma câmera de segurança pode lhe monitorar os movimentos, qual a peculiaridade? Todos esses movimentos do fornecedor são facilmente percebidos pelo consumidor, não existindo, na verdade, qualquer tentativa de oculta-los ou mesmo dissimulá-los, o que não ocorre no mundo virtual, os rastreamentos dos dados do usuário são feitos de forma oculta, seja no momento da escolha do produto, seja no momento da compra.

Assim, a regulação do mundo digital é uma medida que se impõe, pois não poderia a Lei mudar a natureza do mundo digital para fazê-lo adequar-se ao mundo físico, entretanto, seus chamados "códigos"7 de funcionamento podem ser alterados, podendo o governo regular o comércio digital, por exemplo, ou ainda regular o comportamento de provedores de serviço. ${ }^{8}$

\footnotetext{
${ }^{6}$ Nesse exemplo, o autor utiliza-se de caso paradigmático do direito americano: Reno v. American Civil Liberties Union, 521 U.S. 844 de 1006, sendo essa a primeira decisão a versar sobre a proibição de exibição de conteúdo "impróprio" na internet no direito americano. Apesar da decisão não ter sido unânime, considerou-se que a "liberdade de expressão" deveria ser preservada, mantendo-se os conteúdos identificados como "indecentes" online, julgando os termos da Communications Decency Act of 1996, que não traria em seus termos uma definição segura do que se poderia entender por "material impróprio para menores", a vagueza da redação foi considerada pela corte no momento da decisão.

${ }^{7}$ Para LAWRENCE LESSIG, códigos são as regras e instruções intrínsecas ao software e hardware que, juntas, formam o espaço virtual: "As I define the term, code refers to the software and hardware that constitute cyberspace as it is-or, more accurately, the rules and instructions embedded in the software and hardware that together constitute cyberspace as it is. Obviously there is a lot of "code" that meets this description, and obviously the nature of this "code" varies dramatically depending upon the context. Some of this code is within the Internet Protocol (IP) layer, where protocols for exchanging data on the Internet (including TCP/IP) operate.(...)"

${ }^{8}$ Essa ideia de LAWRENCE LESSIG é curiosa pois o texto, muito embora seja de 1999, já adiantou as soluções que chegaram ao mundo digital décadas depois, como o Electronic Commerce Protection Act (ECPA), conhecido como "SPAM bill", que entrou em vigor no Canadá em 15 de janeiro de 2015, a Diretiva Europeia para o Comércio eletrônico 2000/31/CE e, ainda, a recente diretiva que unificou o Direito do Consumidor a 2011/83/EU de 25 de outubro de 2011, que alterou as Diretivas 93/13/CEE do Conselho e a Directiva 1999/44/CE do Parlamento Europeu e do Conselho e que revoga a Diretiva 85/577/CEE do Conselho e a Diretiva 97/7/CE do Parlamento Europeu e do Conselho. No Brasil, há o decreto nº 7.962 de 15 de março de 2013.
} 
O autor entende que o espaço digital comporta quatro possíveis modelos de regulamentação: a regulamentação por Lei (direitos autorais, responsabilidade civil), atuando por meio de sanções ex post; regulamentação por normas derivadas dos próprios provedores de serviço, sendo essas normas indutoras de comportamento, com consequências ex post impostas, seja pelos termos de uso, seja pelos fóruns dos usuários, podendo resultar, inclusive, na exclusão de usuários das plataformas; regulamentação pelo mercado, pela qual muitas empresas que atuam online podem cobrar diretamente por seus serviços ou recorrer a patrocínios, oferecer serviços gratuitos aos usuários, ganhar espaço no mercado online e induzir comportamentos nos consumidores.

A respeito, citamos o autor GRAlf-Peter CAlliess, o mesmo que dissertou sobre mecanismos de governança online, acrescentando-os como forma de indução de comportamento na rede, onde é comum que os provedores de serviço recorram à prestação de serviços de terceiros para administrar seus negócios, seja contratando empresas para administrar verdadeiros fóruns arbitrais online, seja para intermediar e mesmo ranquear a qualidade de serviços oferecidos e consumidores, desenvolvendo empresas atuantes no mercado online, nas chamadas trustmarks, para induzir o comportamento dos consumidores e instituir códigos de conduta que ofereçam maior segurança aos usuários, e mesmo fornecedores que buscam a intermediação de outros provedores para a venda de seus produtos. $\mathrm{O}$ autor utilizou-se de exemplos conhecidos, caso das empresas online Amazon e Ebay. ${ }^{9}$

Por fim, a quarta forma de regulamentação apresentada por LAWRENCE LESSIG seria aquela que diz respeito aos próprios "códigos" da rede de computação, que constituem a própria arquitetura da rede mundial de computadores, conjugando software e hardware. São as regulamentações feitas pelos programadores que determinam o que os usuários digitam, por exemplo, senhas para acesso a determinando serviço, procedimentos de compra que atestam comportamentos concludentes de compra, requisição de informações do usuário ou mesmo garantias de anonimato no momento do acesso. ${ }^{10}$

\footnotetext{
${ }^{9}$ Transnational Consumer Law: Co-Regulation of B2C-E-Commerce, in CLPE Research Paper n⿳3/2007 vol. $03 \mathrm{n}^{\circ} .03,2007$, pp. 04-05.

${ }^{10}$ Commentaries, The Law of The Horse: What Cyberlaw Might Teach, op. cit. (nota 5), pp. 508-509.
} 
Entende o autor que essas quatro formas de regulamentação do espaço digital atuam em conjunto, e conclui, a existência de dois problemas essenciais que distinguem a razão pela qual o direito convencional perde eficácia diante do ambiente digital: o primeiro ele chama de Zoning Speech, visto que, no ambiente digital, as características essenciais de consumidores e fornecedores permanecem ocultas, de forma que as Leis tem eficácia restrita devido à arquitetura do ambiente digital que acabaria gerando um "ruído" em sua aplicação. Outro problema identificado é a respeito da proteção da privacidade, visto que, igualmente devido à arquitetura do sistema do ambiente digital, a fuga de dados do usuário de forma não consentida é uma realidade, já que, no momento da navegação, o comportamento do usuário é capturado, relembrando o autor que referiu-se ao comportamento no mundo real.

De certo, a arquitetura do ambiente digital não permite uma identificação dos usuários, mas apenas uma vinculação do acesso ao endereço de IP, único meio de autenticação utilizado na rede mundial de computadores, fato esse que seria um elemento que comprometeria a eficácia do ordenamento jurídico no momento de identificar as condutas no ambiente digital, daí o desenvolvimento de métodos específicos de navegação que permitem à rede identificar o usuário. No caso de menores, há a navegação para crianças controle parental, no qual as possibilidades de acesso do usuário ficam restritas pela própria rede. ${ }^{11}$

$\mathrm{O}$ autor, curiosamente, acredita que a melhor forma de regulamentar a internet seria por meio de códigos de conduta feitos pelos próprios usuários, bem como, os softwares e provedores de acesso desenvolvendo instrumentos eficazes de identificação de usuários, autorregulando o comportamento dos usuários na rede, não devendo o governo intervir na rede. ${ }^{12}$ Exemplifica com a criação do protocolo $\mathrm{P} 3 \mathrm{P}^{13}$

Na mesma linha, segue GrALF-PETER CALLIESS, o qual defende que o ambiente digital deva ser orientado por certificação conferida por terceiros, viabilizando uma autorregularão do

\footnotetext{
${ }^{11}$ Commentaries, The Law of The Horse: What Cyberlaw Might Teach, op. cit. (nota 5), p. 516

12 "My point is not to endorse such legislation: I think the ideal response for Congress is to do nothing. But if Congress adopted this form of regulation, my view is that it would be both feasible and constitutional. Netscape and Microsoft would have no viable First Amendment objection to a regulation of their code; (...)" Commentaries, The Law of The Horse: What Cyberlaw Might Teach, op. cit. (nota 5), pp. 517.

${ }^{13}$ Em tradução livre significa Plataforma de Preferências para Privacidade, que determina que os usuários sejam informados da coleta de dados ocorrida durante a navegação, ofereçam uma possibilidade de escolha ao usuário sobre quais informações deseja compartilhar, disponível em http://www.w3.org/TR/WD-P3P10-syntax, acesso em 29.08.2017.
} 
setor. ${ }^{14}$ Entretanto, LAWRENCE LESSIG destaca que essa postura resultaria na privatização do sistema legal, defendendo que as relações obrigacionais aperfeiçoadas no meio digital, por exemplo, ficariam submetidas aos códigos de conduta estabelecidos na rede, que se submeteriam não propriamente ao ordenamento jurídico, mas também, e principalmente, à arquitetura da rede. ${ }^{15} \mathrm{O}$ autor destaca que a arquitetura de rede não pode derrogar os princípios do direito das obrigações, e se isso ocorrer, deve haver uma resposta precisa do ordenamento nesse aspecto, de forma que os códigos de conduta na rede devem refletir os valores do ordenamento jurídico, sendo imprescindível que o ordenamento atue in loco para prevenir desvios cometidos pelos códigos de conduta e pela arquitetura de rede.

Conclui Lawrence Lessig que o juiz Frank H. EASTERBROoK não observou que a ausência de uma resposta do ordenamento jurídico à nova realidade do ambiente digital traria, em si, uma ameaça aos próprios valores do ordenamento jurídico, visto que a arquitetura do ambiente digital impulsiona mudanças de valores, seja no direito de propriedade intelectual, seja no direito das obrigações. ${ }^{16}$

Aqui, com a devida vênia, o raciocínio de LAWRENCE LESSIG merece uma importante ponderação. Ainda que ele tenha escrito seu texto em 1999, adiantou uma importante discussão a respeito da arquitetura do ambiente digital forçar uma reformatação de valores ao ordenamento jurídico, defendendo que, ainda que a iniciativa privada deva ganhar espaço na regulamentação da rede, não pode ficar a seu exclusivo critério a determinação de sua formatação legal.

A doutrina italiana empreendeu importante análise sobre o fenômeno informático e sua influência no mundo dos contratos, destacando o papel transformador da tecnologia sobre o fluxo de dados, ponderando que o desenvolvimento do ambiente digital criou novos centro de imputação jurídica que demanda imediata resposta do ordenamento: "la spinta impetuosa dele

\footnotetext{
${ }^{14}$ Nas palavras do autor: "This example highlights that trustmark providers can generate a realm of private order, which rests not only on norms as part of codes of conduct but also on a combination of an insurance for filed payment and alternative dispute resolution procedures. Such na arrangement increases the security level to such an extent that eshopping is rendered more reliable than traditional brick and mortar business dealings, in which customers have to assert their legal rights in court and in which they carry the risk of insolvency. "(Transnational Consumer Law: Co-Regulation of B2C-E-Commerce, op. Cit (nota 9), p. 09.

15 "The cyberspace analog has no equivalent toolbox. Its obligations are not conditioned by the public values that contract law embraces. Its obligations instead flow automatically from the structures imposed in the code," Commentaries, The Law of The Horse: What Cyberlaw Might Teach, op. cit. (nota 5), pp. 530.

${ }^{16}$ Commentaries, The Law of The Horse: What Cyberlaw Might Teach, op. cit. (nota 5), pp. 546.
} 
nuove tecnologie di trasmissione dele informazioni è arrivata ad incidere sul sistema macroeconômico, creando settori di atività di impresa nuovi e prima d'orainesplorate opportunità di mercato per gli operatori economici.", gerando o que o autor chamou de mercantilização de informação, sendo o ambiente digital uma forma aprimorada de transmissão de informações sob as formas mais diferentes possíveis, seja por texto, seja por imagem, vídeo, códigos de programação etc. Toda a forma de dados que possa ser reduzida sob o armazenamento de bits e bites.

De fato, a informação, per se, passou a ser um objeto de extrema relevância jurídica, multiplicando-se os bens jurídicos dela derivados, destacando-se os bancos de dados (que podem apenas armazenar informações ou armazenar, interpretar e coordenar de forma lógica e complexa, criando novo objeto merecedor de tutela jurídica, podendo ser essa nova informação um vídeo, um programa televisivo), sendo a mesma desprovida de natureza corpórea, sem forma e estrutura.

A informação é o objeto do contrato eletrônico, não sendo seu acesso amplo e irrestrito por qualquer usuário, mas sim, acompanhado pela celebração de negócios jurídicos de licenciamento de software, licenciamento de acesso ou mesmo cessão de know-how.

De fato, a difusão da informática e suas inúmeras aplicações nos mais variados setores econômicos acabou, necessariamente, demandando uma resposta jurídica aos novos bens surgidos do mundo digital, no caso, o manuseio, a interpretação e a transmissão de informações, hipótese que a doutrina italiana considerou sem equivalentes no mundo físico. ${ }^{17}$

Interessante pôr em relevo que o mundo digital extravasou seu manuseio do simples computador pessoal, hoje manifestando-se por meio de aplicativos de celular que, cada vez mais, oferecem serviços de alta precisão, que demandam grande envio de informações

\footnotetext{
17 "L'esplosione di Internet e la crescente ramificazione delle reti di telecomuncazioni ha fato sì che il fenomeno digitale, nella sua accezione economica e giuridica, abbracciasse a sè non solo tutta quella mitiade di rapporti commerciali che si concretizzano quotidianamente nelle forme dell'economia tradizionale, ma anche che sviluppasse uma serie di situazioni giuridiche soggetive finora non considerate dal diritto perché esclusive dell'ambiente digitale e non riproducibili in contesti differenti. L'ambiente digitale include ed alimenta dunque $i$ tradizionali traffici commerciale e produce, nello stesso tempo, nuovi interessi giuridici e mai sperimentate forme di scambio tra operatori e tra costoro e gli utente dela rete temelatica." (PIEREMILIO SAMARCO, I Contratti di informatica, in Trattato di Diritto Commerciale e di Diritto Pubblico dell'economia, I Nuovi Contratti Dell'informatica, Sistema e prassi, Padova, Cedam, 2006, pp.177-189).
} 
pessoais, assinatura de termos de uso abrangentes, concessão de direitos personalíssimos e novas formas de contratação de serviços, tais como novas modalidades de intermediação de serviços, como os contratos de Escrow ${ }^{18}$ e os contratos de Cloud Computing.

Além, adentrando-se nas novas modalidades de contrato, a doutrina americana definiu os chamados smart contracts que, em uma tradução livre, se tratam de "contratos inteligentes", baseados em execução automática com máxima eficiência, que serão explorados nos tópicos que seguem.

A primeira conclusão que se tira, portanto, é da importância da discussão em torno do direito digital, destacando sua importância e singularidade, devendo agora prosseguir a presente dissertação a refinar a discussão em torno das novas modalidades de contrato que foram criados pela arquitetura do ambiente digital, com o oferecimento de espécies singulares de contratação, e juridicamente atípicos, mas socialmente típicos, emprestando a terminologia de Pedro Pais de VAsconcelos. ${ }^{19}$

\footnotetext{
${ }^{18}$ Objeto de estudo de mestrado de Silmara Bega NogueIRA, contratos de escrow seriam uma modalidade de garantia para contratos, assemelhado ao depósito, mas depósito de códigos fonte de contratos para sujeito terceiro, que não participa, a princípio, da relação primitiva entre licenciante e licenciatário, mas tratando-se de terceiro que guardará os códigos e os fornecerá ao licenciatário quando o mesmo necessitar, seja para manutenção do software adquirido, ou mesmo proteção na hipótese de ataque que demande ao licenciatário o acesso aos códigos de programação na hipótese de necessidade de reparos ao sistema. O escrow, em si, não é uma modalidade nova de contratação derivada do meio eletrônico, sendo comum na hipótese de compra de terras, venda de ações e depósitos visando construções e fusões e aquisições de empresas, permanecendo com o terceiro depositário valor que assegure a operação principal. O escrow, extrapolando a definição trazida pela pesquisadora, pode ser definido como contrato trilateral acessório de garantia, com deveres e obrigações peculiares a cada um de seus agentes, assemelhando-se ao contrato de depósito no caso do chamado escrow agent, a similaridade é tal que alguns doutrinadores chamam referida modalidade de depósito de Contrato de depósito fiduciário, também chamado de contrato de garantia de acesso ao Código-Fonte (entendido como um código de programação representado por linguagem específica e sofisticada voltada aos analistas para descrever detalhadamente o programa e seus vários passos, constituindo um instrumento de comunicação da forma e conteúdo do programa aos técnicos da área). (Contrato de Escrow: Como garantia de acesso ao Código Fonte, Dissertação de Mestrado, 2004, orientador prof. Newton de Lucca, banca em 04.05.2004)

${ }^{19}$ A atipicidade contratual apresenta-se em plano duplo: legal e social, sendo a legal originada de contratos que, muitas vezes, a prática os consolidou como tipos expressos no ordenamento jurídico, caso da compra e venda, mas não seria, por exemplo, o caso da sociedade por quotas de participação, modalidade contratual plurilateral que nasceu do próprio ordenamento. Destaca o autor que a criação de tipos deve-se a uma "certa inércia na vida jurídica" com uma tendência intrínseca de se manter fórmulas e sistemas cujos resultados são de conhecida eficácia, daí a tentativa de muitas vezes se utilizarem os tipos contratuais para finalidades que não aquelas expressamente previstas, ou misturando cláusulas inerentes a tipos diferentes, originando os chamados contratos atípicos. Sendo que o Estado, muitas vezes, pode interferir na criação contratual, determinando a tipificação, entendendo tipificação como a objetivação de determinadas características, excluindo abstrações incomuns. (Contratos Atípicos, $2^{\mathrm{a}}$ ed. Coimbra, Almedina, 2009, pp. 01-39.)
} 


\section{CONCLUSÃO}

Objetivou a presente dissertação trazer à baila um contrato eletrônico bastante presente no cotidiano dos usuários dos serviços de bens informáticos: o contrato de computação de nuvem.

Muito embora bastante presente, o conhecimento dos usuários em geral sobre a computação de nuvem se restringe às hipóteses de simples armazenamento de dados de forma remota com acesso facilitado por meio de qualquer hardware conectado à rede mundial de computadores.

Entretanto, bem se analisou que a computação de nuvem, mais que um simples armazenamento, ela, em si, provoca um severo efeito disruptivo no mercado global, dado que seu conceito de armazenamento e processamento remoto de dados é ostensivamente utilizado no desenvolvimento de novas tecnologias e, consequentemente, muitos contratos de prestação de serviços eletrônicos de natureza cada vez mais peculiar se desenvolvem, todos utilizandose da enorme quantidade de dados armazenados no Cloud Computing, dados estes que são coletados e interpretados por complexos algoritmos contratuais que auxiliam o usuário, seja na tomada de decisões de atos de compra, seja na completa automatização de faculdades contratuais (smart contracts e inteligência artificial), seja no oferecimento de serviços aprimorados de intermediação de fornecedores e consumidores via aplicativos de celular, casos dos aplicativos de transporte e locação.

Para tanto, apresentou-se, prima facie, uma retrospectiva da discussão travada no direito americano a respeito da existência ou não de inovações que seriam trazidas pelo desenvolvimento do mundo digital para o mundo jurídico. Após, adentrou-se na figura dos contratos eletrônicos, distinguindo os contratos de bens informáticos dos chamados contratos eletrônicos, cuja tomada da congruência negocial é digital.

Destacou-se a capacidade disruptiva dos novos modelos de negócio amparados nas potencialidades do mundo digital, especialmente na computação de nuvem, ressaltando, primeiramente, os bens informáticos que passaram a ser objeto de contratação, destacando-se os softwares e a inicial controvérsia de sua natureza jurídica, passando para a análise dos códigos fonte e dos bancos de dados, sempre trazendo à baila uma comparação da produção 
doutrinária pátria com a europeia e da Common Law. Após, destacou-se a atuação da inteligência digital como elemento essencial, se não determinante, para a celebração e exercício de faculdades contratuais, trazendo-se a análise dos chamados contratos por algoritmo, smart contracts e as inovações da transmissão de dados via blockchain e a criação das criptomoedas, todo decorrência de complexas utilizações de plataforma de computação de nuvem e troca de dados na forma peer to peer, gerando segurança em relações eletrônicas, bem como gerando um fenômeno de desintermediação, de relações online.

Essa discussão se fez imprescindível pois, tanto para o funcionamento dos algoritmos, quanto para a operacionalização do blockchain, é necessário o amplo acesso à informações dos usuários, seja para confrontar dados informados, comprovando sua autenticidade, seja para que os resultados de busca e processamento de dados fossem os mais precisos possíveis, sendo que o armazenamento de dados e o seu tratamento estão todos amparados por sofisticadas plataformas de nuvens públicas.

De certo que os smart contracts e os contratos por algoritmos, para serem eficientes, demandam acesso e análise de informações que a computação de nuvem lhes fornece, para que a melhor decisão diante de determinada circunstância seja igualmente eficaz, de acordo com as últimas milhares de transações de natureza idêntica que foram celebradas, e cujas consequências são ordenadas e analisadas pelos algoritmos embarcados nos softwares.

Relembre-se que o acesso aos dados e sua interpretação/tratamento não é, per se, algo essencialmente novo, mas a grande questão que hoje se apresenta é que os dados não são apenas aqueles armazenados nos data centers de uma empresa ou os dados armazenados nos computadores e telefones, mas sim, todos os dados disponíveis dos usuários que acessam a rede.

Essa vastidão de informações, analisadas pelos complexos aplicativos, tem a enorme potencialidade de gerar resultados imprevisíveis, mesmo para os idealizadores das ferramentas de inteligência artificial, visto que programadas para aprender e antever comportamentos por meio de padrões anteriores apenas por eles facilmente identificáveis.

Assim, os aplicativos que traçam rotas para o usuário via smartphones, ou sugerem determinados produtos ao usuário, ou rastreiam preços no mercado online de produtos que combinam com o perfil de compra do usuário são todos, por exemplo, em essência, contratos 
de computação de nuvem, nos quais as informações pessoais do usuário (perfil de compra, localização e potencial financeiro) são remetidos à nuvem, e lá, interpretados e processados, retornando na forma de serviço para o hardware do usuário.

De fato, o elemento catalizador para o avanço tecnológico foi a facilitação ao acesso de dados, sendo os mesmos colocados à disposição pela computação de nuvem. De fato, o fenômeno é de tal forma relevante que, hoje, dificilmente se adquire um hardware que já não venha embarcado com serviços de backup, armazenamento em nuvem de fotos, lembrete de senhas, logins automáticos, identificador de fisionomias de parentes e amigos, filtros inteligentes de mensagens eletrônicas.

Daí se evidencia a relevância da presente dissertação em se analisar o regime jurídico no qual está inserto o contrato de Cloud Computing, relembrando sua natureza massificada, por contratação adesiva.

Apurou-se que a pouca produção jurídica sobre o tema, principalmente em âmbito nacional, é evidente, seja pela ignorância tecnológica com relação às novas ferramentas eletrônicas, seja diante da satisfação dos usuários que estão utilizando dos serviços e computação de nuvem, o que se reflete no baixo grau de jurisdicionalização das demandas e, igualmente, a presença de meios alternativos de soluções de disputas e presença de códigos de conduta particulares, os quais os próprios provedores de nuvem aderem.

Todavia, a satisfação não exclui o fato dos serviços apresentarem riscos notáveis, sendo passíveis de incidência da legislação protetiva do sistema do consumidor, restando saber os limites do suporte fático.

No sistema europeu, a discussão despertou relevante debate a respeito da incidência ou não da legislação protetiva sobre os contratos de computação de nuvem, sendo a jurisprudência europeia bastante firme em manter a dicção da Convenção de Bruxelas e sua definição funcional de consumo, afastando do campo de incidência do referido diploma, até mesmo usuários pessoas físicas que se utilizam de softwares online para fins pessoais e empresariais.

Com essa definição, não concordam a grande maioria dos doutrinadores, que defendem uma análise contratual da relação, observando as assimetrias de poderes e a falta de especialidade e conhecimento técnico do contratante diante do contratado. 
No Brasil, a discussão ocorre sob o conceito da "vulnerabilidade", especialmente quanto à chamada vulnerabilidade tecnológica, que tem servido para se abrir portas para a incidência da legislação protetiva às empresas que contratam serviços extremamente especializados no mundo virtual.

Relembre-se, por oportuno, que os contratos de Cloud Computing têm, por elemento cerne, seus termos de contratação padrão, o que, per se, não basta para se atrair a legislação protetiva, mas é elemento diferenciador que, tomado em contexto, pode ser suficiente para que a relação negocial entabulada seja analisada sob o prisma do microssistema protetivo do consumidor, relembrando-se sua distinção dos contratos de Outsourcing e contratos de Sistemas Informáticos.

Assim, a legislação protetiva do consumidor tem apoio doutrinário para incidir, inclusive, nas relações empresariais da computação de nuvem, especialmente nos casos de empresas de pequeno e médio porte e, principalmente startups.

Mas resta imprescindível que a atividade sofra uma eficaz regulamentação, sendo essa a grande discussão nas novas diretivas europeias sobre o tratamento e processamento de dados, bem como nos Acts do Common Law.

Observou-se que os ordenamentos jurídicos têm apenas optado por disciplinar o regime jurídico da proteção de dados, relegando à computação de nuvem a regulamentação pelos particulares, que tem editado códigos de conduta para a disciplina do setor, especialmente quanto à forma de fornecimento do serviço, compatibilidade, portabilidade de dados e privacidade/segurança de dados.

No Brasil, há um projeto de lei que busca disciplinar justamente a atividade do Cloud Computing: o Projeto de Lei $\mathrm{n}^{\circ} 5.344$ de 2013, no qual se destacam inúmeras peculiaridades da atividade.

A Lei traz em sua redação uma natureza didática e impõe aos provedores do serviço de cloud uma responsabilidade na proteção de dados e no tratamento das informações, voltandose para uma preocupação social com o serviço, portabilidade de dados e compatibilidade de acesso para os diversos modelos de hardware que operam no país, evidente preocupação social. 
Quanto ao microssistema protetivo pátrio, o mesmo, já há muito, disciplinou o conceito de vulnerabilidade tecnológico como verdadeiro filtro de incidência da legislação mais benéfica, de forma que as empresas têm a possibilidade de invocar a legislação protetiva na hipótese de contratações de computação de nuvem. Entretanto, mesmo diante dessas hipóteses, a vulnerabilidade precisa ser cabalmente demonstrada, visto que empresas de grande porte sequer celebram diretamente contratos de computação de nuvem, mas sim, de Outsourcing.

De fato, o contrato de computação de nuvem impõe um severo desafio ao sistema protetivo, visto a existência de uma forte tendência de gereralização de aplicação da legislação do consumidor, mesmo diante de um cenário nos quais as inovações tecnológicas têm beneficiados, além de provedores de serviços online, mas igualmente os usuários, devendo-se ponderar se, efetivamente ponderar se a aplicação generalizada do Código de Defesa do Consumidor é possível nesses termos.

Prudente, de fato, que uma legislação seja feita e o serviço de nuvem disciplinado, devendo a lei, por meio de diálogo de fontes, ser interpretada em conjunto com o Código de Defesa do Consumidor e Código Civil, ponderando-se pela vulnerabilidade tecnológica que parece ser ínsita a contratação, mas observando, igualmente, o caráter subjetivo daquele que a contrata, na hipótese de consumidor pessoa jurídica e presumida na hipótese de pessoa física para uso pessoal 



\section{BIBLIOGRAFIA}

Agrifoglio, Giangabriele. Abuso di dipendenza economica e l'asimetria nei contratti d'impresa (B2b). Contratto e impresa, Dialoghi com la giurisprudenza civile e commerciale diretti da Francesco Galgano, v.VI, ano 24, Padova, Cedam, 2008.

Armbrust, Michael, Fox, Armando, GrifFith, Rean, JosePh, Anthony D., Katz, Randy H, Konwinski, Andrew, Lee, Gunho, Patterson, David. A., Rabkiln, Ariel, Stoica, Ion, ZAHARIA, Matei, Above the Clouds: A Berkeley View of Cloud Computing, in Technical Report No. UCB/EECS-2009-28, 10 de fevereiro, 2009, disponível em http://www.eecs.berkeley.edu/Pubs/TechRpts/2009/EECS-2009-28.html.

AZEVEDo e AzEREDo, João Fábio, Reflexos do emprego de sistemas de inteligência artificial nos contratos, dissertação (mestrado em direito) - Faculdade de Direito da Universidade de São Paulo, São Paulo, 2014.

All, Paula M. Mercosur apud FERNÁNDEZ ARROYO, Diego P. (Org.). Consumer Protection in International Private Relationships, Assunção, Center for the Studies of Law, Economy and Politics - CEDEP, 2010.

AlPA, Guido. Compendio del Nuovo Diritto Privato, Torino, Utet, 1985.

. I Contratti dei consumatori e la disciplina generale dei contratti e del rapporto obbligatorio. Rivista di Diritto Civile, mar/2006.

Il recepimento della direttiva comunitaria sulle clausole abusive nei contratti dei consumatori. Estudos de Direito do Consumidor, v.1, Centro de Estudos de Direito do Consumidor da Faculdade de Coimbra, 1999.

. I Diritti dei consumatori e degli utente, un comento alle leggi 30.7.1998 n. 281 e 24.11.2000 n. 340 e al decreto legislativo 23.4.2001 n. 224, Milano, Giuffré, 2001.

. Il Diritto dei Consumatori, $3^{\mathrm{a}}$ ed., Roma, Laterza, 2002. 
. Manuale di Diritto Privato, $6^{\mathrm{a}}$ ed., Padova, Cedam, 2009.

.Corso di Diritto Contrattuale, $1^{\mathrm{a}}$ ed., Padova, Cedam, 2006.

; Chinè, Giuseppe; Gazzoni, Francesco; Realmonte, Francesco; Rovelli, Luigi. Trattato di Diritto Privato, Diretto da Mario Bessone. Il Contratto in Generale, t. II, vol. XIII, Torino, Giappichelli, 1999.

Amadeo Auletta, Tommaso. Le Clausole Vessatorie nella Giurisprudenza apud Massimo BIANCA, Cesare (Org.). Le condizioni generali di contratto, v. I, Milano, Giuffrè, 1979.

ANDRADE AdDARIo, Marilsen. Conceituação de consumidor: destinatário final ou uso não profissional? Revista de Direito do Consumidor, ano 19, v.75, jul. set./2010.

, Zeno-Zencovich. Vincenzo. Italian Private Law, Abingdon, Routledge

Cavendish, 2007.

Antunes Varela, João de Matos, Das Obrigações em Geral, v.1, 10ª ed., Coimbra, Almedina, 2003.

BATISTA PEREIRA, Alexandre. Em torno do assim chamado consumidor intermediário. Revista de Direito do Consumidor, ano 20, v.79, jul. set./2011.

Bega NogueIRA, Silmara, Contrato de Escrow: Como garantia de acesso ao Código Fonte, Dissertação de Mestrado, 2004, orientador prof. Newton de Lucca, banca em 04.05.2004.

Bernardes De Melo, Marcos, Teoria do Fato Jurídico, Plano da Existência, 15aaed., São Paulo, Saraiva, 2008.

Beckstead, Desmond, Gellatly, Guy, The growth and development of new economy industries, in The Canadian Economy in Transition Research Paper, $n^{\circ}$ 11-622-MIE, v. 2, maio, 2003, disponível em http://ssrn.com/abstract=1403384. 
Bradshaw, Simon; Millard, Christopher; Walden, Ian. Contracts for Clouds: Comparison and Analysis of the Terms and Conditions of Cloud Computing Services. Queen Mary University of London, School of Law Legal Studies Research paper, nº 63/2010.

Bueno de Godoy, Cláudio Luiz. Função Social do Contrato, 4a ed., São Paulo, Saraiva, 2012.

Buonocuore, Vincenzo. Contratti del Consumatore e contratti d'impresa. Rivista di Diritto Civile, ano 41, v.1, jan. fev./1995.

CALliess, Gralf-Peter, Transnational Consumer Law: Co-Regulation of B2C-E-Commerce, in CLPE Research Paper n⿳3/2007, vol. 03 nº 03, 2007.

Calvão da Silva, João. Venda de Bens de Consumo, 4ª ed., Coimbra, Almedina, 2010. Responsabilidade Civil do Produtor, $1^{\mathrm{a}}$ ed., Coimbra, Almedina, 1999.

Caval, Cássio, Direito das Obrigações, Mora e Utilidade, Rio de Janeiro, Fundação Getúlio Vargas, 2011

CAVAlli, Sabina. Natureza jurídica da obrigação de implantação de software em contratos de licença de uso concluídos com usuário pessoa jurídica, e as consequências do seu não cumprimento. Revista de Direito do Consumidor, ano 17, v.65, jan. mar./2008.

Corrêa da Silva, Alice Marinho, Quintanilha de almeida, Mariana, Pereira Martins, Vitor Teixeira, Computação, comércio eletrônico e prestação de serviços digitais, sua tributação pelo ICMS e ISS, 1ed., São Paulo, Almedina, 2017.

CHIESA, Clélio, Competência para Tributar as operações com programas de computador (softwares), in Revista Tributária e de Finanças Públicas, vol. 36, nº107, janeiro, 2001.

CONSTANZA, Mario. Condizioni generali di contratto e contratti stipulati daí consumatori apud Massimo BiancA, Cesare; AlPA, Guido (Orgs.), Le Clausole Abusive nei contratti stipulati com $i$ consumatori, L'a attualizatione dela diretiva comunitaria del 5 aprile 1993, nº 14, Verona, Cedam, 1996. 
Couto E Silva, Clóvis Veríssimo do, A Obrigação como Processo, São Paulo, Fundação Getúlio Vargas, 2006.

Crescenzo Marino, Francisco Paulo. Contratos Coligados no Direito Brasileiro, $1^{\mathrm{a}}$ ed., São Paulo, Saraiva, 2009.

Cross, Stuart R., Agency, Contract and Intelligent Software Agents. International Review Of Law Computers and Technology, v. 17, nº2, jul./2013.

Cunningha, Alan, ReED, Chris, Consumer Protection in Cloud Environments, in C. Millard (coord.), Cloud Computing Law, Oxford University Press, 2013.

,Caveat Consumer? Consumer Protection \& Cloud

Computing Part 1, Issues of Definition in the Cloud, in Queen Mary School of Law Legal Studies Research Paper, $\mathrm{n}^{\mathrm{o}}$ 130/2013, 5 de julho, 2015, disponível em https://ssrn.com/abstract=2202758 ou http://dx.doi.org/10.2139/ssrn.2202758

CuRA Mariano, João. Responsabilidade Contratual do Empreiteiro pelos Defeitos da Obra, $3^{\mathrm{a}}$ ed., Coimbra, Almedina, 2008

Dal Pai Moraes, Paulo Valério. Código de Defesa do Consumidor, O princípio da vulnerabilidade no contrato, na publicidade, nas demais práticas comerciais, $3^{\mathrm{a}}$ ed., Porto Alegre, Livraria do Advogado, 2009.

Dias Pereira, Alexandre, A Proteção do consumidor no quadro da Directiva sobre comércio eletrónico, in Estudos de Direito do Consumidor, n², Coimbra, Almedina, 2000.

DonedA, Danilo, Perspectivas para o combate ao spam, in Direito \& Internet, Aspectos Jurídicos Relevantes, vol. 2, São Paulo, Quartier Latin, 2008.

EASTERBROOK, Frank H., Cyberspace And The Law of The Horse, University of Chicago Legal Forum n ${ }^{\circ} 207,1996$. 
ECHEGARAY, Fabiàn, Consumers' reactions to product obsolescence in emerging markets: the case of Brazil, in Journal of Cleaner Production, vol. 134, parte A, 15 de outubro de 2016.

ETTORE NANNI, Giovanni. Relação de consumo: uma situação jurídica em interação entre o Código de Defesa do Consumidor e o Código Civil apud Lotufo, Renan, Rodrigues Martins, Fernando (coord.), 20 Anos do Código de Defesa do Consumidor, Conquistas, Desafios e Perspectivas, São Paulo, Saraiva, 2011.

Faillace, Stefano. Contratti stipulati com i consumatori. Contratto e impresa, Dialoghi com la giurisprudenza civile e commerciale diretti da Francesco Galgano, v. I, ano 20, Padova, Cedam, 1996.

FRIED, Charles, Contract as Promise, traduzido por DuARTE, Sérgio, Rodrigues CorRÊA, André, Contrato como Promessa, Uma teoria da Obrigação Contratual, São Paulo, Elsevier, 2008.

FERraZ JÚnIOR, Tércio Sampaio, Introdução ao Estudo do Direito, Técnica, Decisão, Dominação, 6aed., São Paulo, Atlas, 2008.

CRuZ, Guilherme Ferreira da. Princípios Constitucionais das Relações de Consumo e Dano Moral, Outra Concepção, São Paulo, Saraiva, 2008.

. Teoria Geral das Relações de Consumo, $1^{\mathrm{a}}$ ed., São Paulo,

Saraiva, 2014.

FinOCHIARO, Giusella. I Contratti ad oggetto Informatico. Contratto e impresa. Dialoghi com la giurisprudenza civile e commerciale diretti da Francesco Galgano, v.28, ano 12, Padova, Cedam, 1993.

FranCO, Flávio. O Impacto do Marco Civil da Internet nas atividades de E-commerce. Apud ARTESE, Gustavo. Marco Civil da Internet, Análise Jurídica sob uma perspectiva empresarial, São Paulo, Quartier Latin, 2015. 
Freitas Rodrigues, Raúl Carlos. O Consumidor no Direito Angolano, Coimbra, Almedina, 2009.

FORRAY, Vincent. O direito Europeu do consumidor e a possibilidade de uma contrateoria do contrato. Revista de Direito do Consumidor, ano 21, v.81, jan. jul./2012.

Galgano, Francesco, Diritto ed economia alle soglie del nuovo millennio, in Contratto e impresa, v.16, $\mathrm{n}^{\mathrm{0}} 1,2000$.

GASSER, Urs, Cloud Innovation and the Law: Issues, Approaches, and Interplay, in Ther Berkman Center for internet \& society at Harvard University, nº 2014-7, 17 de março, 2014.

GiLmore, Grant, The Death of Contract, $2^{\mathrm{a}}$ ed., Michigan, The Ohio State University Press, 1995.

Gomes, Orlando. Contrato de Adesão, Condições Gerais dos Contratos, São Paulo, Revista dos Tribunais, 1972.

GotTLIEB, Spencer, Instalallation failure, How the predominant purpose test has perpetuated softwrae's uncertain llegal status under the uniform comercial code, in Michigan Law Review, vol. $113, \mathrm{n}^{\circ} 739$.

GrInBerg, Ruben. Bitcoin: An Innovative Alternative Digital Currency, in Hastings Science \& Technology Law Journal, v, 4, abril, 2011.

Junqueira de Azevedo, Antônio (Org.). Princípios do Novo Código Civil Brasileiro e outros temas, Homenagem a Tullio Ascarelli, 2ª ed., São Paulo, Quartier Latin, 2010.

- Estudos e Pareceres de Direito Privado, Relação Jurídica que não é de consumo. Destinatário final. Cláusula abusiva, São Paulo, Saraiva, 2004.

O Direito pós moderno e a codificação. Revista da Faculdade de Direito da Universidade de São Paulo, v.94, 1999. 
Kern, Christoph. A proteção do consumidor pelos Tribunais: Desafios dos fenômenos de massa, Giordania, Lisiane Maria (Trad.). Revista de Direito do Consumidor, ano 21, v.83, jul. set./2012.

HALlE, Elizabeth. When is a Company Consumer? Nottingham Law Journal, nº52, 2004.

Held, David, McGrew, Anthony, Governing Globalization: Power, Authority and Global Governance, Boldmin, Polity Press, 2002.

Scholz, Lauren Henry, Algorithmic Contracts, in Stanford Technology Law Review, Forthcoming, disponível em SSRN https://ssrn.com/abstract=2747701.

HeRman V. Benjamin, Antônio; Marques, Claudia Lima; Roscoe Bessa, Leonardo. Manual de Direito do Consumidor, $4^{\mathrm{a}}$ ed. São Paulo, Revista dos Tribunais, 2012.

IPPOLIO, Fulvio Sarzana. I contratti di Internet e del commercio eletrônico, Milão, Giuffrè, 2001 .

JHERING, Rudolf Von, Culpa in Contrahendo, ou indemnização em contratos nulos ou não chegados à perfeição, traduzido por MotA PINTO, Paulo, Coimbra, Almedina, 2008.

K. Yu, Peter, Towards The Seamless Global Distribution of Cloud Content, Privacy and Legal Issues in Cloud Computing, Edward Elgar Publishing, 2015, pp.180-2013, disponível em https://ssrn.com/abstract=2478583.

KIM, Nancy S., Contracts and Digital Content, Expanding the Scope of the Principles of the Law of Software Contracts to Include Digital Content, in Tulane Law Review no 84, 2010, disponível em SSRN, https://ssrn.com/abstract=1597366.

Kshetri, Nir, Cloud Computing in Developing Economies, in IEEE Computer, v. 43, $\mathrm{n}^{\mathrm{o}} 10$, pp. 47-55, 2010, disponível em SSRN: https://ssrn.com/abstract=2015387. 
Lessig, Lawrence, Commentaries, The Law of The Horse: What Cyberlaw Might Teach, in Harvard Law Review, v. 113, disponível em https://cyber.harvard.edu/works/lessig/finalhls.pdf.

Lima Marques, Cláudia. Contratos no Código de Defesa do Consumidor. O novo regime das relações contratuais, $6^{\mathrm{a}}$ ed., São Paulo, Revista dos Tribunais, 2011.

. Diálogo entre o código de Defesa do Consumidor e o novo Código Civil, do "Diálogo das Fontes" no Combate às Cláusulas abusivas. Revista de Direito do Consumidor, ano 12, v.45, jan. mar./2003.

. Confiança no Comércio Eletrônico e a proteção do Consumidor, $1^{\mathrm{a}}$ ed., São Paulo, Revista dos Tribunais, 2004.

LôBo, Paulo. Direito Civil, Contratos, 2a ed., São Paulo, Saraiva, 2014.

LorenzetTI, Ricardo Luis. Tratado de los Contratos, La informática e internet em los Contratos, t. III, Buenos Aires, Rubinzal-Culzoni, 2000.

. Tratado de los Contratos, Contrato de Franquicia, t. I, Buenos Aires, Rubinzal-Culzoni, 2000.

. Redes Contractuales: Conceptualización Jurídica, Relaciones Internas de Colaboración, Efectos frente a terceiros. RDC, v. 28, out/1998.

; MENKE, Fábio (Trad.). Comércio Eletrônico, São Paulo, Revista dos Tribunais, 2004.

MANTELERO, Alessandro, Il contratto per l'erogazione alle imprese di servizi di cloud computing, in Contratto e Impresa, $\mathrm{n}^{\circ} 4-5$, 2012, pp. 1216-1218, disponível em SSRN: https://ssrn.com/abstract=2142050. 
MacneIL, Ian R. The New Social Contract, Yale University Press, 1980 apud ANDRAdE LAmparelli, Alvamar de Campos (Trad.); Rodriguês CorrêA, André (Rev.). O Novo Contrato Social, Rio de Janeiro, Elsevier, 2009.

Magalhães Dias, Lucia Ancona Lopez de. Publicidade e Direito, $2^{\mathrm{a}}$ ed., São Paulo, Revista dos Tribunais, 2013.

Marighetto, Andrea. Proposta de leitura comparativa e sistemática do Código do Consumo Italiano. Revista de Direito do Consumidor, ano 20, v.80, out-dez/2011.

Massimo Bianca, Cesare. Diritto Civile, 2a ed., vol. III, Milano, Giuffrè, 2000.

MAROTTA-WURGLER, Florencia, Will Increased Disclosure Help? Evaluating the Recommendations of the ALI's 'Principles of the Law of Software Contracts, in New York University and Economic Working Papers, ${ }^{\circ} 10$, 2014, disponível em SSRN https://ssrn.com/abstract=2497163.

Mathews Hunt, Kate, CloudConsumer: contracts, codes \& the law, in Computer Law \& Security Review, n³1, Gold Coast, Elsevier, 2015.

Martins Costa, Judith, A Boa-Fé no Direito Privado, Critérios para a sua Aplicação, São Paulo, Marcial Pons, 2015.

Marston, Sean; BAndyopadhyay, Zhi Li; Zhang, Subhajyoti Juheng. Cloud Computing The Business Perspective, v. 51, § 1, Abril/2011.

Mathews Hunt, Kate. Cloud Consumer: contracts, codes \& the law, computer law \& security review, $n^{\circ}$ 31, Elsevier, 2015.

Menezes Cordeiro, António. Da modernização do Direito Civil, Aspecto Gerais, v.1, Coimbra, Almedina, 2004.

MessineO, Francesco. Il Contrato in Genere, t.1, Milano, Giuffrè, 1973. 
Millard, Christopher, Hon, W. Kuan, Cloud Technologies and Services, in C. Millard (coord.), Cloud Computing Law, Oxford University Press, 2013.

,Cloud Computing vs Traditional Outsourcing - Key

Differences, in Computers \& Law, vol. 23, n4 , Outubro/Novembro, 2012, disponível em SSRN: https://ssrn.com/abstract=2200592, acesso em novembro de 2017.

, Hon, W. Kuan, WALDEN, Ian, Negotiating Cloud Contracts: Looking

at Clouds from both sides now, in Stanford Technology Law Review, vol. 16, ${ }^{\circ} 1$, fim de 2012, disponível em http://stlr.stanford.edu/pdf/cloudcontracts.pdf.

.Bradshaw, Simon, Walden, Ian, Contracts for Clouds:

Comparison and Analysis of the Terms and Conditions of Cloud Computing Services, in Queen Mary University of London, School of Law Legal Studies Research Paper nº3, 2010, disponível em http://ssrn.com/abstract=1662374.

Bradshaw, Simon, Walden, Ian, Standard Contracts for Cloud Services, in C. MillaRD (coord.), Cloud Computing Law, Oxford University Press, 2013

Minervini, Enrico. Contratti dei consumatori e tutela coletiva nel codice del consumo. Contratto e impresa, Dialoghi com la giurisprudenza civile e commerciale diretti da Francesco Galgano, v. III, ano 22, Padova, Cedam, 2006.

Miragem, Bruno. Jurisprudência comentada, Tribunal de Justiça do Rio de Janeiro, AC 0005587-12.2007.8.19.0209. Revista do Direito do Consumidor, nº 81, 2012.

Morato, Antonio Carlos. Pessoa Jurídica Consumidora, $1^{\text {a }}$ ed., São Paulo, Revista dos Tribunais, 2008.

Morais Carvalho, Jorge. Os Contratos de Consumo, Reflexão sobre a Autonomia Privada no Direito do Consumo, Coimbra, Almedina, 2012.

MoreIRA Alves, João Carlos, Direito Romano, 14 a ed., Rio de Janeiro, Forense, 2008. 
Motta Filho, Marcello Martins, Ensaio Jurídico Sobre A Computação em Nuvem (Cloudcomputing), in Revista Tributária e de Finanças Públicas, vol. 116, 2014.

PrICE, W. Nicholson, Black-Box Medicine, in Harvard Journal of Law \& Technology, v. 28, $\mathrm{n}^{\circ} 02$, primavera, 2015.

Nobrega Pizarro, Sebastião, Comércio Eletrónico Contratos Electrónicos e informáticos, Coimbra, Almedina, 2005.

Noronha NajJarian, Ilene Patrícia, O capitalismo eletrônico informático. Sistemas 'High Frequency Trading' ou 'algotraders das corretoras de valores. Plataformas de crowdfunding, in Direito \& Internet, Marco Civil da Internet, Lei 12.965/2014, tomo II, São Paulo, Quartier Latin, 2015.

Novais ReIS, Iuri Ribeiro, O Princípio da Vulnerabilidade como núcleo central do Código de Defesa do Consumidor, in Revista dos Tribunais, v. 956, junho, 2015.

Paes De Vasconcelos, Pedro. Contratos Atípicos, $2^{\mathrm{a}}$ ed., Coimbra, Almedina, 2009.

PATti, Salvatore. Codice Civile Tedesco, Bürgerliches Gesetzbuch, Milão, Giuffrè, 2005.

Pellegrini Grinover, Ada; Herman de Vasconcellos e Benjamin, Antonio; Roberto Fink, Daniel; Brito Filomeno, José Geraldo; Nery Júnior, Nelson; DenARI, Zelmo. Código brasileiro de Defesa Consumidor, comentado pelos autores do anteprojeto, Direito Material, v.1, 10 ed., Rio de Janeiro, Forense, 2011.

Perlingieri, Pietro. Manuale di Diritto Civile, $6^{\mathrm{a}}$ ed., Napoli, Edizioni Scientifiche Italiane, 2007.

Perchinunno, Maria Colomba. Collegamento negoziale e contratti informatici: dai contratti sul software all'open source. Contratto e impresa, Dialoghi com la giurisprudenza civile e commerciale diretti da Francesco Galgano, v. I, ano 12, Padova, Cedam, 2005. 
Pestana De Vasconcelos, Luís Miguel. O Contrato de Franquia (Franchising), 2a ed., Coimbra, Almedina, 2010.

Pietros Peres, Fabiana. Definição de consumidor na União Europeia, na OEA e no Mercosul, in Revista de Direito do Consumidor, ano 20, v.80, out-dez/2011.

Pinto Monteiro, António. Do direito do Consumo ao código do consumidor. Estudos de Direito do Consumidor, v.1, Centro de Estudos de Direito do Consumidor da Faculdade de Coimbra, 1999.

Prietos Peres, Fabiana, Definição de Consumidor da União Europeia, na OEA e no Mercosul: A recepção de microempresas como consumidor como proteção à pequena empresa que inclui em sua definição a pessoa jurídica, in Revista de Direito do Consumidor, $\mathrm{n}^{\circ} 80$, ano 20, out/dez., 2011.

PRISCOLI, Lorenzo Delli. La tutela del consumatore fra accertamento dela non professionalità del suo agire, tutela dela concorrenza e affidamento dela controparte. Contratto e impresa. Dialoghi com la giurisprudenza civile e commerciale diretti da Francesco Galgano, v.VI, ano 23, Padova, Cedam, 2007.

Quick, Darren, Raymond Choo, Kim-Kwang, Google Drive: Forensic Analysis of Cloud Storage Data Remnants, in Journal of Network and Computer Applications, Forthcoming, 15/0ut, 2013, disponível em https://ssrn.com/abstract=2340234.

RASKIN, Max, The Law and Legality of Smart Contracts, in Georgetown Law Technology Review, vol. 1, $\mathrm{n}^{\circ}$ 305, 2017, disponível em https://perma.cc/673G-3ANE, acesso em outubro de 2017.

Rosa Pereira, Cintia, Ricardo, Bruno, A Proteção dos dados pessoais na Fase de Coleta: Apontamentos sobre a adjetivação do consentimento implementada pelo artigo $7^{\circ}$, incisos VIII e IX do Marco Civil da Internet a partir da Human Computer Interaction e da Privacy by defaut, in N. De Lucca, A. Simão Filho, C. Rosa Pereira De Lima, Direito \& Internet III, Tomo I, São Paulo, Quartier Latin, 2015. 
RODAU, Andrew. Computer Software Contracts: A Review Of The Caselaw. Akron Law Rev., $n^{\circ} 41$, v. $45,1987-1988$.

Computer Software Contracts, a Review of the caselaw, in Software Law Journal, vol. 2, no 77,100, 1987.

Rodrigues, Cunha. As Novas Fronteiras dos problemas de consumo. Estudos de Direito do Consumidor, v.1, Centro de Estudos de Direito do Consumidor da Faculdade de Coimbra, 1999.

RopPo, Vincenzo. Il Contratto, Milano, Giuffrè, 2001.

. Il Contratto del Duemila, $3^{\mathrm{a}}$ ed., Torino, Giappichelli, 2011.

. O Contrato, Coimbra, Almedina, 2009.

Roscoe Bessa, Leonardo. Relação de Consumo e Aplicação do Código de Defesa do Consumidor, $2^{\text {a }}$ ed., v. 39, São Paulo, Revista dos Tribunais, 2009.

RuSSO, Ennio. Imprenditore debole, imprenditore-persona, abuso di dipendenza economica, terzo contrato. Contratto e impresa, Dialoghi com la giurisprudenza civile e commerciale diretti da Francesco Galgano, v. I, ano 25, Padova, Cedam, 2009.

SAVelyev, Alexander, Contract Law 2.0: "Smart" Contracts as the Beginning of the end of Classic Contract Law, in National Researsh University Higher School of Economics, Working Papers Series Law, WPBRP nº71, 2016.

Sammarco Pieremilio, I Contratti di informatica, in Trattato di Diritto Commerciale e di Diritto Pubblico dell'economia, I Nuovi Contratti Dell'informatica, Sistema e prassi, Padova, Cedam, 2006.

,Prefazione, in Trattato di Diritto Commerciale e di Diritto Pubblico dell'economia, Il Contratto Telematico, v. 41, Padova, CEDAM, 2002. 
,La conclusione del contrato nella Direttiva sull'e-commerce, in Trattato di Diritto Commerciale e di Diritto Pubblico dell'economia, Il Contratto Telematico, v.41, Padova, CEDAM, 2002.

, I Nuovi Contratti dell'informatica, Sistema e Prassi in Trattato di Diritto Commerciale e di Diritto Pubblico dell'economia, Il Contratto Telematico, v.41, Padova, Cedam, 2006.

,Il mondo open Source ed i suoi profili contrattuali, in Trattato di Diritto Commerciale e di Diritto Pubblico dell'economia, Il Contratto Telematico, v.41, Padova, CEDAM, 2006.

,I Contratti Relativi ai sistemi informatici, in Trattato di Diritto Commerciale e di Diritto Pubblico dell'economia, Il Contratto Telematico, v.41, Padova, CEDAM, 2006.

Santiago Moreno, Ismael, La Revolución de la Tecnología de las Cadenas de Bloques y su Impacto en los Sectores Económicos, in Working paper II: Tecnologías disruptivas, disponível em https://ssrn.com/abstract=2846816 ou http://dx.doi.org/10.2139/ssrn.2846816.

SAntos Sombra, Thiago Luís, Adimplemento contratual e cooperação do credor, São Paulo, Saraiva, 2011.

SASSEN, Saskia The State and Globalization, in R.B. HALL, T.J. BIERSTEKER, The Emergence of Private Authority in Global Governance, Cambridge, Cambridge University Press, 2002.

SCAFF, Fernando Campos, Responsabilidade Do Empresário Pelo Fato Do Produto E Do Serviço, Do Código Civil Ao Código De Proteção E Defesa Do Consumidor, in Revista dos Tribunais, RT n ${ }^{\circ}$ 737, março, 1997. 
ScotT, Robert E., The Case for Formalism in Relational Contract, in Northwestern University Law Review $\mathrm{n}^{\circ} 00-13$, maio/2000, pp. 2, 5-11, disponível em http://papers.ssrn.com/paper.taf?abstract_id=215129, acesso em 19.06.2016.

Silva Matos, Karla Cristina da Costa. O Valor Econômico da Informação nas Relações de Consumo, $1^{\text {a }}$ ed., São Paulo, Almedina, 2012.

SorkIn, David E. Technical and Legal Approaches to Unsolicited Electronic Mail, in University of San Francisco Law Review, v. 35, nº 2, Inverno, 2001.

SousA RiBeIRo, Joaquim. O Problema do Contrato, as cláusulas contratuais gerais e o princípio da liberdade contratual, Coimbra, Almedina, 1999.

SURDEN, Harry, Machine Learning and Law in Washington Law Review, v. 89, nº 1, 2014.

TASNeEm, FARISA, Electronic Contracts and Cloud Computing, in Journal of International Commercial Law and, vol. 9, nº 2, 2014.

TeIXeIRA, Tarcisio, Contratos de Software: Apontamentos sobre suas espécies, in Revista dos Tribunais, vol. 976, $\mathrm{n}^{\circ}$ 15, fev., 2017

TAKEMI KATAOKA, Eduardo. A coligação contratual, $1^{\mathrm{a}}$ ed., Rio de Janeiro, Lumen Juris, 2008.

Tepedino, Gustavo. A aplicabilidade do Código Civil nas relações de consumo: diálogos entre o Código Civil e o Código de Defesa do Consumidor apud Lotufo, Renan; Rodrigues Martins, Fernando (Coord.). 20 Anos do Código de Defesa do Consumidor, Conquistas, Desafios e Perspectivas, São Paulo, Saraiva, 2011.

. Abuso de poder econômico e abuso de poder contratual. Revista dos Tribunais, $\mathrm{n}^{\circ}$ 715, maio, 1995.

Tomasevicius Filho, Eduardo, O Marco Civil da Internet e as liberdades de Mercado, in N. De Lucca; A. SimÃo Filho, C.R.Pereira De Lima, Direito \& Internet III, Marco Civil da Internet Lei $n^{\circ}$ 12.965/2014, t.2, v.3, São Paulo, Quartier Latin, 2015. 
TOMASETti JR., Alcides. Abuso de poder econômico e abuso de poder contratual, in Revista dos Tribunais, $\mathrm{n}^{\circ}$ 715, maio, 1995.

TrabuCCHI, Alberto. Istituzioni di Diritto Civile, 44a ed., Padova, Antonio Milani, 2009.

Varela, Antunes. Direito do Consumo. Estudos de Direito do Consumidor, v.1, Centro de Estudos de Direito do Consumidor da Faculdade de Coimbra, 1999.

VITO NAPOLI, Emílio. Le Condizioni generali di contratto nella Giurisprudenza apud MASSIMO BIANCA, Cesare (Org.). Le condizioni generali di contratto, v.I, Milano, Giuffrè, 1979.

Von Bar, Christian; Clive, Eric. Principles Definitions and Model Rules of European Private Law, Draft Common Frame of Reference (DCFR), v.1, Munique, European Law Publishers, 2009. Principles Definitions and Model Rules of European Private Law, Draft Common Frame of Reference (DCFR), v.2, Munique, European Law Publishers, 2009. . Principles Definitions and Model Rules of European Private Law, Draft Common Frame of Reference (DCFR), Franchise, v.3, Munique, European Law Publishers, 2009.

ZACCARIA, Alessio. Fondamenti e sviluppi del diritto privato europeo. Revista de Direito do Consumidor, ano 17, v.65, jan. mar./2008.

Zimmermann, Reinhard. The New German Law of Obligations, Historical and Comparative Perspectives, Oxford Press, 2009.

Zeno-Zencovich, Vincenzo; D’ORAZIO, Roberto. Profili di responsabilità contrattuale e aquiliana nella fornitura di servizi telematici. Dir. inf. 1990. , Informazione (profili civilistici). Digesto, v. 9, $4^{\mathrm{a}}$ ed., disc. priv., sez. civ., UTET 1993. 
W. Kuan, Hon; Christopher, Millard; WALDEn, Ian. Negotiating Cloud Contracts: Looking At Clouds From Both Sides Now. Stanford Technology Law Review, v. 16, $\mathrm{n}^{\circ}$ 01, Outono/2012. 